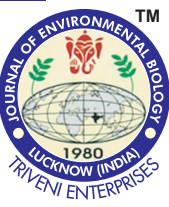

\title{
Morphological and toxigenic study of Aspergillus flavus from indoor air
}

\begin{tabular}{lll}
\hline Paper received: 31.10 .2017 & Revised received: 01.05.2018 & Re-revised received: 15.06 .2018 \\
\hline
\end{tabular}

\section{Authors Info \\ S. Nayak ${ }^{1 *}$, U. Dhua ${ }^{2}$ and S. Samanta ${ }^{3}$ \\ 'Odisha Biodiversity Board, Regional Plant Resource Centre Campus, Bhubaneswar-751 015, India \\ ${ }^{2}$ Crop Protection Division, ICAR-National (Central), Rice Research Institute, Cuttack-753 006, India ${ }^{3}$ ICAR-Central Tuber Crop Research Institute-Regional Centre, Bhubaneswar-753 017, India \\ *Corresponding Author Email : shubhransu.cri@gmail.com}

\section{Edited by \\ Dr. R. B. Raizada}

\section{Reviewed by}

Professor Yash Pal Sharma

Dr. Surya Prakash

Dr. Ravindra Khaiwal

\section{Abstract}

Aim : In the current investigation thirty four $A$. flavus cultures were isolated from indoor air samples of some farmers' house in coastal region of Odisha. Production of aflatoxin B1 and the pattern of formation of sclerotia by the isolates were studied in vitro.

Methodology : Morphological study and production of sclerotia were carried out by observing fungal colonies on culture media. Conidiophores were identified under Phase contrast microscope. Detection of aflatoxin $\mathrm{B} 1$ was done by Thin Layer Chromatography technique.

Results : The isolates exhibited variation in their colony characteristics and pattern of sclerotia formation. Overall $44 \%$ A. flavus isolates produced stable aflatoxin B1 and $41 \%$ were producers of sclerotia. About $32 \%$ A. flavus isolates produced both sclerotia and aflatoxin B1. Most of the non toxigenic isolates failed to form thick mycelia mat on $\beta$-CD-PDAmedia. Aflatoxin and sclerotia producing isolates were found more in coastal districts than inter-coastal regions. No significant variation in the pattern of sclerotia production was observed among isolates in less aerobic (sealed plates) and aerobic (unsealed plates) condition, however isolates had slightly more preference towards less aerobic environment for sclerotia production. The size of sclerotia was found to be inversely related to number of sclerotia.

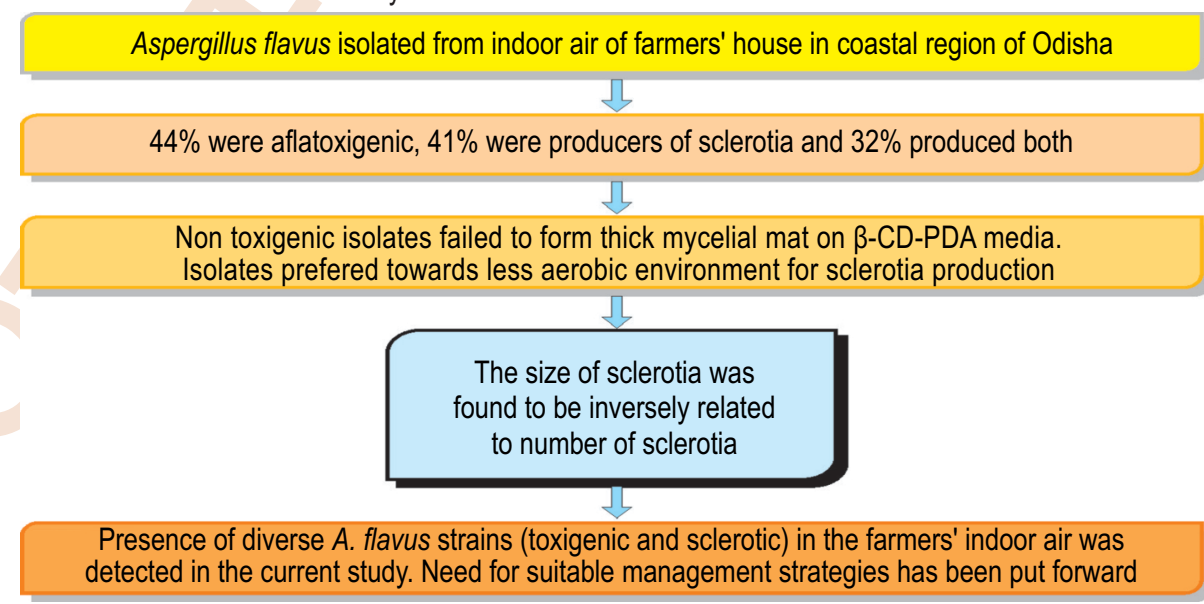

Interpretation : The presence of diverse A. flavus strains in farmers' indoor air, having the ability to produce either aflatoxin or sclerotia or both, may lead to serious health implications. This issue need to be addressed and a suitable way for proper management of indoor environment of farmers' need to be designed.

Key words: Aspergillus flavus, Aflatoxin, $\beta$-Cyclodextrine, Indoor air

How to cite : Nayak, S., U. Dhua and S. Samanta: Morphological and toxigenic study of Aspergillus flavus from indoor air. J. Environ. Biol., 40, 648-654 (2019). 


\section{Introduction}

Aspergillus flavus (A. flavus) is ubiquitous fungus commonly occurring in soil, water, decaying vegetation and in indoor air (Ghosh et al., 1997; Gorny et al., 2002; Nielsen, 2003; Adhikari et al., 2004; Khan and Karuppayil, 2012; Lai et al., 2015). Inhalation of conidia and ingestion of $A$. flavus contaminated food is thought to be the cause of acquiring invasive aspergillosis (Balasubramanian et al., 2012; Fakruddin et al., 2015). This fungus also infects and produces aflatoxins in a wide variety of agricultural commodities such as maize, corn, vegetables, spices, chilies, sorghum, groundnut and other oil seeds and rice (Reddy et al., 2009; Nayak et al., 2014; Oyewale, 2015; Bala et al., 2016). Since the infamous episode of Turkey- $X$ disease in the United Kingdom in 1960, aflatoxins have been reported to be carcinogenic, mutagenic and immunosuppressive agent. Among the mycotoxins, aflatoxin B1 has been classified as group IA carcinogen by International Agency for Research on Cancer (IARC, 2002; Amaike and Keller, 2011).

Though, A. flavus is strictly a mitotic fungus, besides producing conidia asexually it also produces specialized resistant structures known as sclerotia. Sclerotia are pigmented, compact aggregates of specialized hyphae which are vestige of cleistothecia incapable of ascospore production. These can resist unfavorable environmental conditions and are capable of remaining dormant for long periods (Cotty, 1988; Horn et al., 2016). Sclerotia are important survival structures in the life cycle of many fungi, stored with reserve food materials and sometimes detached and remain dormant until favorable conditions occur (McAlpin, 2001). A. flavus isolates that produce sclerotia can be divided in to two types of strains, $L$ and $S$ on the basis of morphological, physiological and genetic criteria (Bayman and Cotty, 1991; Cotty, 1989). 'S' strain isolates produce numerous small sclerotia (<400 $\mu$ m in diameter) and fewer conidia than ' $L$ ' strain isolates. Typical isolates $(L)$ of $A$. flavus may produce only $B$ aflatoxins or no aflatoxins at all and all $S$ strain isolates (atypical isolates by Saito et al., 1986) reported to date produce large quantities of aflatoxins. Some strains produce only $B$ aflatoxins and others produce both $B$ and $G$ aflatoxins. Formation of sclerotia by $A$. flavus has been linked positively, as well negatively with aflatoxin production.

The climate of Odisha is characterized by higher rainfall, temperature and humidity which form a favourable condition for growth of storage fungi. The poor farmers in this region usually keep harvested paddy inside their house due to lack of separate storage facility. Paddy associated fungi like $A$. flavus and its fragments may contaminate the indoor air in this situation. Continuous exposure of the inhabitants to these conditions make them prone to inhale fungal mycelial fragments, conidia, sclerotia, fungal metabolites, mycotoxins like aflatoxins etc. which act as indoor air biocontaminants (Gorny et al., 2002), a condition similar to 'sick building syndrome'. Numerous studies have shown that exposure to fungi may be associated with acute toxic effects, allergies and asthma (Khan and Karuppayil, 2012).
There seems to be no reports available on the presence of Aspergillus flavus in the indoor air of farmers' house at coastal region of Odisha, hence the present study was undertaken to isolate Aspergillus flavus strains from air samples of farmers' indoor environment of coastal region of Odisha and to study the pattern of sclerotia and aflatoxin B1 production.

\section{Materials and Methods}

Isolation, identification and study of culture characters of $A$. flavus isolates: Thirty four $A$. flavus isolates (ID A-1 to A-34) were taken for analysis in the current study. The A. flavus cultures were isolated by passive air sampling method with settle culture plates. Potato Dextrose Agar (PDA) plates were exposed for $1 \mathrm{~min}$ to the open respirable indoor air of farmer's house from five coastal districts of the state of Odisha, India such as Balasore, Dhenkanal, Puri, Nayagarh and Khurdha. Plates were then incubated at $28^{\circ} \mathrm{C}$ for 3 days and the fungal colonies were isolated on PDA plates. A. flavus cultures were identified by observing the colour of mycelia on culture plate having typical lime green or yellow green colour of mycelia as described by Fakruddin et al. (2015). Identification of $A$. flavus isolates was further confirmed by observing the typical structural arrangement of conidiophores under microscope (Olympus) as described by Koh and Tseng (1975). All fungal isolates were preserved at $4^{\circ} \mathrm{C}$ on PDA slants in the Plant Pathology Division of National Rice Research institute, Cuttack, India. The culture characters of isolates (colour of colony front and back), formation of sclerotia and production aflatoxin were further observed by growing isolates on Czapekdox Agar media (CZA) and $\beta$-Cyclodextrine Potato Dextrose Agar ( $\beta$-CD-PDA) medium. The composition of CZA was constituted of $30 \mathrm{~g}$ Sucrose, $3 \mathrm{~g} \mathrm{NaNO} 3,0.5 \mathrm{~g} \mathrm{MgSO}_{4}$ $7 \mathrm{H}_{2} \mathrm{O}, 0.5 \mathrm{~g} \mathrm{KCl}, 1 \mathrm{~g} \mathrm{~K}_{2} \mathrm{HPO}_{4}, 15 \mathrm{~g}$ Agar and $1000 \mathrm{ml}$ distilled water (final pH $6 \cdot 2 \pm 0 \cdot 2$ ). Colour of isolates was observed by comparing with RHS colour chart (The Royal Horticultural Society, London: Flower Council of Holland, Leiden).

Detection of aflatoxin B1 by Thin Layer Chromatography: To detect the production of aflatoxin $B 1$, isolates were grown in PD and $\mathrm{CZ}$ broth for seven days. The mycelial mat thus formed was harvested and blot dried and sclerotia (if any) were separated by using a small sterilized paint brush. Mycelia was ground with extraction buffer $(60 \%$ Methanol with $0.5 \% \mathrm{KCl})$ and then centrifuged at $12000 \mathrm{rpm}$ for $10 \mathrm{~min}$ at $40 \mathrm{C}$. The supernatant was used for detection of aflatoxin B1 by Thin Layer Chromatography method. Silica gel $\mathrm{G}$ (Hi-media) $(20 \mathrm{~g})$ mixed with $40 \mathrm{ml}$ of distilled water and applied manually on a clean glass plate $(22 \times 21 \mathrm{~cm})$ to make a thin and uniform gel. After air drying properly it was kept inside oven at $121^{\circ} \mathrm{C}$ for one hour and then cooled at room temperature. A 20 $\mu$ l each of standard aflatoxin B1 and sample was spotted at $4 \mathrm{~cm}$ from the bottom of the plate. The plate was developed with $100 \mathrm{ml}$ of developing solvent containing chloroform to acetone at 90:10 proportions. After development, the plate was dried and spots were visualised and documented under $360 \mathrm{~nm}$ on an UV Trans Illuminator (WEALTEC) 
Study of vegetative growth and sclerotia production: To study the sclerotia characteristics, isolates were cultured on Czapekdox Agar media. After inoculation, isolates were grown in three types of culture environments. One set of culture plates were sealed tightly with paraffin film strips making a less aerobic or anaerobic like environment and another set was kept as such, thereby growing in aerobic environment. One set of cultures were also grown in CZA slants with cotton plugging. Periodical observations were taken for colony diameter, sclerotia number, colour, texture, shape and microscopic size. Variations in vegetative growth and sclerotia production pattern were studied from data of Balanced Analysis of Variance (ANOVA) using CROPSTAT Version3.0 software. Correlations between different parameters were determined using DATA ANALYSIS option from Microsoft Excel sheet.

\section{Results and Discussion}

The presence of allergenic Aspergillus flavus in indoor air of many areas of India including rice grain handling areas have been reported (Adhikari et al., 2004; Ghosh et al., 1997). Evancho et al. (2001) discussed about the sampling of indoor air in food processing areas. Hence, in the current investigation thirty four $A$. flavus cultures A-1 to A-34 were isolated from the indoor air of farmers' house from five coastal districts of Odisha. Production of aflatoxin and sclerotia by these $A$. flavus cultures (A-1 to A-34) was investigated. The isolated $A$. flavus cultures had typical yellow green or lime green colony with typical conidiophores structures. The culture colour 'on surface' of all the isolates were recorded to have RHS no. 146A, 147A \& 152A on CZA and 146A, 148A \& 152A on $\beta$-CD-PDA indicating various shades of yellow-green colour. However, reasonable variations were observed in the colour of colony reverse (observed at petridish bottom) in both the culture media, which was actually the colour of mycelia mat formed by the isolates. The reverse of colony colour in most of the isolates varied between shades of yellow orange and grayed orange group on CZA. Mycelia mat was not formed by $50 \%$ of the isolates on $\beta$-CD-PDA media, hence the reverse back was noted as 'colourless'.

Variation in the yellow colouration of mycelia mat (back of the colony) might be due to large number of secondary metabolites produced by $A$. flavus cultures. Lin and Dianese (1976) first linked this yellow pigmentation with the production of aflatoxins which are also secondary metabolites. These bright yellow pigments have been known as anthraquinone pigments which are associated with the aflatoxin biosynthetic pathway in Aspergillus spp. (Shier et al., 2005). Abbas (2011) also found many indoor toxigenic $A$. flavus strains producing yellow pigments. However, some reports have delimited the linkage of yellow pigmentation with the production of aflatoxins where some media were identified in which semi quantitative differences were observed (Davis et al., 1987; Gupta and Gopal, 2002; Pitt and Hocking, 2009). In the current study no such correlation could be firmly established, but generally it could be observed that most of the nontoxigenic isolates failed to form mycelia mat on $\beta-C D-P D A$ media.
Sclerotia formation was observed in $41 \%$ of the isolates on CZA media and in $21 \%$ on $\beta$-CD-PDA media. Production of sclerotia in the strain A28 isolated from Balasore district was much higher than other isolates on $\beta$-CD-PDA (Table 1). Nearly half of the isolates showed the ability to produce sclerotia in either of the media but CZA media proved to be containing better substrates for this purpose. This might be due to the optimal balance of carbon and nitrogen in CZA along with sodium nitrate as an excellent source of nitrogen (Nesci et al., 2006; McAlpin, 2004).

As far as toxigenic potential is concerned, fifty percent of the $A$. flavus isolates were found to have the ability to produce aflatoxin B1 when both media were considered. Only two isolates, $A 11$ and $A 28(5 \%)$ were detected to produce aflatoxin B1 on CZ broth by TLC method whereas $41 \%$ isolates produced aflatoxin $\mathrm{B} 1$ on $\beta$-CD-PD broth (Table 1). Most of the isolates which were unable to form mycelia mat on $\beta-C D-P D A$ medium were also unable to produce sclerotia and aflatoxin $\mathrm{B} 1$.

Production of aflatoxins by $A$. flavus isolates could be detected better in $\beta$-CD-PD broth than $C Z$ broth. The $\beta$-cyclo dextrines present in this medium have excellent cavities for exciting the fluorescence responses of aflatoxins B1 and G1 through the formation of inclusion complexes. Addition of this complex to a suitable agar medium enhances detection of aflatoxin production by $A$. flavus and $A$. parasiticus by blue fluorescence under 365-nm light (Fente et al., 2001; Galaverna et al., 2008). Indoor air of farmers' house of Dhenkanal district was devoid of sclerotia as well as aflatoxin B1 producing A. flavus and less numbers of such isolates were also obtained from Puri district. However, A. flavus isolates from indoor air of farmers' house in Balasore district were prolific producers of both sclerotia and aflatoxin B1, with $A 28$ being the most aggressive one. Dhenkanal district is almost $100 \mathrm{~km}$ away from sea coast, hence seems to be an inter-coastal region. On the other hand, Balasore is a coastal district with high humidity, temperature and receive long periods of rain, making it a congenial environment for fungal growth and production of secondary metabolites like aflatoxins.

Overall, $44 \%$ A. flavus isolates were found to be aflatoxigenic and $41 \%$ were producers of sclerotia when both media are considered. Among the isolates which produced aflatoxin $\mathrm{B} 1,73 \%$ of isolates produced sclerotia whereas $78 \%$ of sclerotia producers also produced aflatoxin B1. Out of the total number (34) of $A$. flavus isolates, $32 \%$ produced both sclerotia and aflatoxin. All the sclerotia producing isolates were found to be L-type strains i.e., the size of the sclerotia were more than $400 \mu \mathrm{m}$ (Table 3).

Sclerotia development and aflatoxin biosynthesis have been found to be closely related in previous studies. Increased production of the aflatoxin precursors is associated with progressive decrease in sclerotial size, alteration in sclerotial shape and weakening in the sclerotial structure (Chang et al., 2002). Duran et al. (2007) reported that production of aflatoxin by Aspergillus flavus is regulated by veA, a gene also necessary for 
Table 1: Culture characters, sclerotia and toxin producing ability on CZA and $\beta$-CD-PDAmedia of $A$. flavus cultures isolated from indoor air of farmers' house

\begin{tabular}{|c|c|c|c|c|c|c|c|c|}
\hline \multirow{2}{*}{ Isolate ID } & \multicolumn{2}{|c|}{$\begin{array}{c}{ }^{*} \text { Culture colour on CZA } \\
\text { media }\end{array}$} & \multicolumn{2}{|c|}{$\begin{array}{c}\text { Culture physiology on } \\
\text { CZ broth }\end{array}$} & \multicolumn{2}{|c|}{$\begin{array}{c}\text { *Culture colour on } \beta-C D \text { - } \\
\text { PDA media }\end{array}$} & \multicolumn{2}{|c|}{$\begin{array}{c}\text { Culture physiology on } \\
\beta-C D-P D \text { broth }\end{array}$} \\
\hline & $\begin{array}{l}\text { On } \\
\text { surface }\end{array}$ & $\begin{array}{l}\text { Petri dish } \\
\text { bottom } \\
\text { (mycelia mat) }\end{array}$ & Sclerotia & $\begin{array}{l}\text { Afla } \\
\text { toxin }\end{array}$ & $\begin{array}{l}\text { On } \\
\text { surface }\end{array}$ & $\begin{array}{l}\text { Petridish } \\
\text { bottom } \\
\text { (mycelia mat) }\end{array}$ & $\begin{array}{l}* * * \\
\text { Sclerotia }\end{array}$ & $\begin{array}{l}* * \\
\text { Afla } \\
\text { toxin }\end{array}$ \\
\hline $\mathrm{A} 1$ & $146 \mathrm{~A}$ & $20 \mathrm{~A}$ & - & - & $148 \mathrm{~A}$ & colorless & - & - \\
\hline $\mathrm{A} 2$ & $146 \mathrm{~A}$ & $18 \mathrm{~A}$ & - & - & $148 \mathrm{~A}$ & colourless & - & + \\
\hline $\mathrm{A} 3$ & $146 \mathrm{~A}$ & $20 \mathrm{~A}$ & - & - & $146 \mathrm{~A}$ & colourless & - & - \\
\hline A4 & $146 \mathrm{~A}$ & $20 \mathrm{~A}$ & - & - & $148 \mathrm{~A}$ & colourless & - & - \\
\hline A5 & $146 \mathrm{~A}$ & $19 \mathrm{~A}$ & - & - & $146 \mathrm{~A}$ & colourless & - & - \\
\hline A6 & $146 \mathrm{~A}$ & $20 \mathrm{~A}$ & - & - & $148 \mathrm{~A}$ & colourless & - & - \\
\hline A7 & $146 \mathrm{~A}$ & $20 \mathrm{~A}$ & - & - & $146 \mathrm{~A}$ & colourless & - & - \\
\hline A8 & $146 \mathrm{~A}$ & $20 \mathrm{~A}$ & - & - & $146 \mathrm{~A}$ & colourless & - & - \\
\hline A9 & $146 \mathrm{~A}$ & $21 \mathrm{~B}$ & - & - & $146 \mathrm{~A}$ & colourless & - & - \\
\hline A10 & $147 \mathrm{~A}$ & $20 \mathrm{~A}$ & - & - & $146 \mathrm{~A}$ & colourless & - & - \\
\hline A11 & $147 \mathrm{~A}$ & $22 \mathrm{~A}$ & - & + & $146 \mathrm{~A}$ & $160 \mathrm{~B}$ & - & - \\
\hline $\mathrm{A} 12$ & $146 \mathrm{~A}$ & $20 \mathrm{~B}$ & - & - & $146 \mathrm{~A}$ & colourless & - & - \\
\hline A13 & $146 \mathrm{~A}$ & $18 \mathrm{~B}$ & + & - & $146 \mathrm{~A}$ & colourless & - & - \\
\hline A14 & $146 \mathrm{~A}$ & $21 \mathrm{~B}$ & + & - & $146 \mathrm{~A}$ & $17 \mathrm{~B}$ & + & ++ \\
\hline A15 & $146 \mathrm{~A}$ & $20 \mathrm{~A}$ & + & - & $146 \mathrm{~A}$ & $17 \mathrm{~A}$ & - & ++ \\
\hline A16 & $146 \mathrm{~A}$ & $18 \mathrm{~A}$ & + & - & $146 \mathrm{~A}$ & $17 \mathrm{C}$ & + & ++ \\
\hline A17 & $146 \mathrm{~A}$ & $18 \mathrm{~A}$ & + & - & $146 \mathrm{~A}$ & colourless & - & - \\
\hline A18 & $152 \mathrm{~A}$ & $19 \mathrm{~A}$ & - & - & $146 \mathrm{~A}$ & colourless & - & - \\
\hline A19 & $146 \mathrm{~A}$ & $18 \mathrm{~A}$ & - & - & $146 \mathrm{~A}$ & $12 \mathrm{C}$ & - & - \\
\hline A20 & $152 \mathrm{~A}$ & $19 \mathrm{~A}$ & + & - & $146 \mathrm{~A}$ & $17 \mathrm{~B}$ & + & ++ \\
\hline A21 & $152 \mathrm{~A}$ & $19 A$ & + & - & $146 \mathrm{~A}$ & $17 \mathrm{~A}$ & + & ++ \\
\hline A22 & $152 \mathrm{~A}$ & $163 B$ & - & - & $152 A$ & $12 B$ & - & - \\
\hline A23 & $152 \mathrm{~A}$ & $163 B$ & + & - & $146 \mathrm{~A}$ & $17 \mathrm{~A}$ & + & ++ \\
\hline A24 & $146 \mathrm{~A}$ & $20 \mathrm{~A}$ & - & - & $146 \mathrm{~A}$ & $12 C$ & - & - \\
\hline A25 & $146 \mathrm{~A}$ & $19 \mathrm{~A}$ & + & - & $146 \mathrm{~A}$ & $17 \mathrm{~B}$ & + & +++ \\
\hline A26 & $146 \mathrm{~A}$ & $18 \mathrm{~A}$ & + & - & $146 \mathrm{~A}$ & colourless & - & ++ \\
\hline A27 & $146 \mathrm{~A}$ & $164 C$ & + & - & $146 \mathrm{~A}$ & $12 \mathrm{C}$ & - & - \\
\hline A28 & $152 \mathrm{~A}$ & $18 \mathrm{~B}$ & + & + & $152 A$ & $164 \mathrm{~B}$ & ++++ & ++++ \\
\hline A29 & $146 \mathrm{~A}$ & $18 \mathrm{~B}$ & - & - & $146 \mathrm{~A}$ & colourless & - & - \\
\hline A30 & $146 \mathrm{~A}$ & 164 & + & - & $146 \mathrm{~A}$ & $12 \mathrm{C}$ & - & ++ \\
\hline A31 & $146 \mathrm{~A}$ & $164 C$ & + & - & $146 \mathrm{~A}$ & $12 \mathrm{C}$ & - & ++ \\
\hline A32 & $146 \mathrm{~A}$ & $164 B$ & - & - & $146 \mathrm{~A}$ & colourless & - & ++ \\
\hline A33 & $146 \mathrm{~A}$ & $164 C$ & - & - & $146 \mathrm{~A}$ & $12 \mathrm{C}$ & - & - \\
\hline A34 & $146 \mathrm{~A}$ & $164 C$ & - & - & $146 \mathrm{~A}$ & $17 \mathrm{C}$ & - & + \\
\hline
\end{tabular}

Colourless: No mycelia mat formed by the isolate on petridish bottom. * Culture colour as per RHS colour chart as follows: 14 to 23 yellow orange group; 144 to 154 is yellow green group; 160 greyed yellow; 163 to 165 greyed orange group. A, B, C and D etc along with RHS no. indicate the various shades ** Sclerotia of L type

${ }^{* * *}$ Quantity of aflatoxin: (-) No toxin; (+) Less than $2 \mu \mathrm{g} \mathrm{ml}^{-1} ;(++) 2 \mu \mathrm{g} \mathrm{ml}^{-1}$ to $9 \mu \mathrm{g} \mathrm{ml}^{-1} ;(+++) 10 \mu \mathrm{g} \mathrm{ml} \mathrm{l}^{-1}$ to $25 \mu \mathrm{g} \mathrm{ml}^{-1} ;(++++)$ More than $25 \mu \mathrm{g} \mathrm{m}{ }^{-1}$

sclerotial formation. However, not all isolates of $A$. parasiticus and A. flavus which produce aflatoxins have the ability to produce sclerotia. The results of many investigations suggested that sclerotia formation was poorly related to aflatoxin production (Razzaghi-Abyaneh et al., 2006). Some of clinical A. flavus isolates could have aflatoxin and sclerotia producing ability, but not necessarily all aflatoxigenic $A$. flavus isolates were capable of producing sclerotia (Dehghan et al., 2008). Singh et al. (2015) also observed no association between morphological-diversity and toxigenic potential of $A$. flavus isolates from pea nut. Though it is generally agreed upon that aflatoxin biosynthesis and sclerotial development in $A$. flavus and $A$. parasiticus are related, the relationship between these processes is yet to be defined. In the present study such correlation was observed on a higher percentage in indoor $A$. flavus isolates. However, more vigorous study is required to establish a significant correlation, might be more than $90 \%$. Even if all isolates in the current study were of L-strains, higher concentrations of aflatoxin could be 
Table 2: Comparison of sclerotia production by A. flavus isolates in sealed and unsealed plates and slants

\begin{tabular}{|c|c|c|c|c|}
\hline \multirow{2}{*}{ Isolate } & \multicolumn{3}{|c|}{ Sclerotia formed Per $\mathrm{cm}^{2}$} & \multirow{2}{*}{$\begin{array}{l}\text { Mean sclerotia no. } \\
\text { per Isolate }\end{array}$} \\
\hline & Sealed & Unsealed & Slant & \\
\hline A13 & 0 & 22 & 15 & 12 \\
\hline A27 & 32 & 9 & 16 & 19 \\
\hline A17 & 25 & 18 & 20 & 21 \\
\hline A26 & 38 & 39 & 12 & 30 \\
\hline A31 & 45 & 40 & 12 & 32 \\
\hline $\mathrm{A} 30$ & 51 & 42 & 10 & 34 \\
\hline $\mathrm{A} 16$ & 76 & 45 & 17 & 46 \\
\hline A15 & 72 & 70 & 22 & 55 \\
\hline A14 & 77 & 65 & 30 & 57 \\
\hline A25 & 60 & 93 & 18 & 57 \\
\hline A21 & 91 & 73 & 11 & 58 \\
\hline A23 & 95 & 82 & 12 & 63 \\
\hline A20 & 102 & 106 & 11 & 73 \\
\hline A28 & 141 & 138 & 70 & 116 \\
\hline $\begin{array}{l}\text { Mean sclerotia no in } \\
\text { each environment }\end{array}$ & 65 & 60 & 20 & \\
\hline
\end{tabular}

LSD: Least Significance Difference. *Significant at $p<0.05 ;$ LSD for mean sclerotia no. per isolate:14.18; LSD for mean sclerotia no. in each; environment : 7.09 and LSD for isolate and Sclerotia no. : 24.5

detected in culture broth and sclerotia. In general isolates showed little more preference to less aerobic environment over aerobic environment and least preference to slant environment to produce sclerotia though there was isolate specific preferences (Table 2). On an average isolates produced 65,60 and 20 numbers of sclerotia $\mathrm{cm}^{-2}$ in less aerobic, aerobic and slant environment respectively (LSD 7.09). When all three environments are taken into consideration, isolates showed variable ability to produce sclerotia
(LSD 14.18) and the number of sclerotia produced ranged from 12 numbers $\mathrm{cm}^{-2}$ by $\mathrm{A} 13$ to 116 numbers $\mathrm{cm}^{-2}$ by $\mathrm{A} 28$. A13 didn't produce any sclerotia in less aerobic environment. Overall, the sizes of the sclerotia were found to be inversely related to the number of sclerotia produced by isolates in all the three environments depicted by $r$ value of -0.49 (Fig 1). Accordingly, the average sizes of sclerotia were $675.8 \mu \mathrm{m}, 744.8 \mu \mathrm{m}$ and $810.6 \mu \mathrm{m}$ in sealed, unsealed and slants, respectively, which

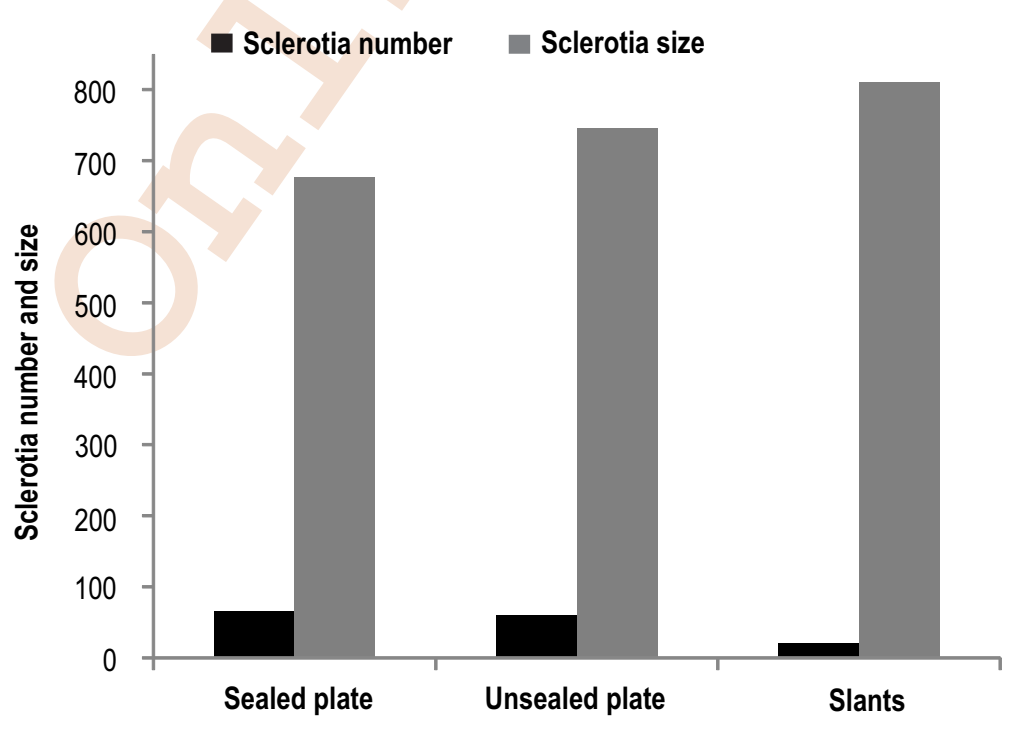

Fig 1: Overall comparison between sclerotia number and size produced by $A$. flavus isolates in sealed and unsealed plates and slants 
Table 3: Comparison of sclerotia size (diameter in $\mu \mathrm{m}$ ) produced by isolates of $A$. flavus in sealed and unsealed plates and slants

\begin{tabular}{lllll}
\hline \multirow{2}{*}{ Isolate } & \multicolumn{3}{c}{ Diameter of sclerotia $(\boldsymbol{\mu m})$} & \multicolumn{2}{c}{$\begin{array}{l}\text { Mean sclerotia size. } \\
\text { per Isolate }\end{array}$} \\
\cline { 2 - 5 } & Sealed & Unsealed & Slant & 524.2 \\
\hline A28 & 566.66 & 577 & 429 & 702.1 \\
A14 & 735.33 & 715 & 656 & 705.7 \\
A31 & 681.6 & 685 & 750.6 & 721.1 \\
A20 & 714.33 & 672.33 & 776.66 & 748.4 \\
A16 & 713 & 782.66 & 749.66 & 766.6 \\
A17 & 718.66 & 740.33 & 841 & 771.6 \\
A15 & 750 & 721.33 & 843.66 & 775.1 \\
A21 & 720.33 & 756.33 & 848.66 & 782.9 \\
A25 & 778 & 759 & 811.66 & 789.0 \\
A27 & 679.33 & 676.66 & 1011 & 811.7 \\
A30 & 780 & 791 & 801.5 & 864.4 \\
A26 & 867 & 882.66 & 685.66 & 984.95 \\
A23 & 758 & 725.66 & 1109.67 & \\
A13 & 0 & 943.66 & 1025.33 & \\
Mean Sclerotia size in each & 675.8 & 744.8 & 810.6 & \\
environment & & & &
\end{tabular}

LSD: Least Significance Difference. ${ }^{*}$ Significant at $p<0.05$; LSD for mean sclerotia size per isolate: 66.08 ; LSD for mean sclerotia size in each environment: 33.04 and LSD for isolate and Sclerotia size: 114.46

depicted significant variation with a LSD value of 33.04. Isolate A13 produced the largest size sclerotia $(984.95 \mu \mathrm{m})$ and A28 had the smallest sized sclerotia $(524.2 \mu \mathrm{m})$. The sclerotia size of rest of the isolates ranged between $702.1 \mu \mathrm{m}$ to $793.8 \mu \mathrm{m}$ (LSD at $p<0.05$ was 66.08), except isolate A23 and A26 which had sclerotia size $811.7 \mu \mathrm{m}$ and $864.4 \mu \mathrm{m}$ respectively.

Reports suggested that sclerotia production may partly act as defense mechanism against oxidative stress (Chang, 2009). Physiologically sclerotia differentiation was mainly inhibited by the increase in intracellular $\mathrm{H}_{2} \mathrm{O}_{2}$ concentration (Grintzalis et al., 2014). Usually, it has been observed that lowering the oxygen concentration results in inhibition or suppression of sclerotia or cleistothecia formation in fungal species that naturally produce them during their life cycle (Rai et al., 1967; Barkai-Golan, 2001). Pathogenic species like A. flavus are capable of growing at low concentration of oxygen, but not completely in anaerobic environment. The geography, environment and climate of coastal region of Odisha is favorable for fungal growth and proliferation, including $A$. flavus. The presence of reasonable population of such isolates having the ability to produce both aflatoxin and sclerotia at the same time puts forward a serious issue to be addressed in this region to avoid the so called "Sick building", as observed in some part of the globe like in America and Europe. Designing of suitable management practice of this fungus by eco-friendly approach needs further research.

\section{Acknowledgments}

Authors are grateful to the Director of ICAR-National (Central) Rice Research Institute, Cuttack for providing necessary facilities to conduct the experiments. Authors are also thankful to the Member Secretary/Chairman, Odisha Biodiversity Board, Bhubaneswar.

\section{References}

Abbas, H.K., M.A.Weaver, B.W. Horn, I. Carbone, J.T. Monacell and W.T. Shier: Selection of Aspergillus flavus isolates for biological control of aflatoxins in corn. Toxin. Rev., 30, 59-70 (2011).

Adhikari, A., M.M. Sen, S. Gupta-Bhattacharya and S. Chanda: Volumetric assessment of airborne fungi in two sections of a rural indoor dairy cattle shed. Env. Int., 29, 1071-1078 (2004).

Amaike, S. and N.P. Keller: Aspergillus flavus. Ann. Rev. Phytopath., 49, 107-133 (2011).

Bala, P., D. Gupta and Y.P. Sharma: Mycoflora and natural aflatoxin contamination in dried quince seeds from Jammu, India. J. Env. Biol., 37, 101-106 (2016).

Balasubramanian, R., P. Nainar and A. Rajasekar: Airborne bacteria fungi, and endotoxin levels in residential microenvironments: A case study. Aerobiol., 28, 375-390 (2012).

Barkai-Golan, R.: Postharvest Diseases of Fruits and Vegetables: Development and Control. Elsevier, 2001.ISBN 0080539297 9780080539294, p.: 124 (2001)

Bayman, P. and P.J. Cotty: Vegetative compatibility and genetic diversity in the Aspergillus flavus population of a single field. Can. J. Bot., 69, 1707-1711 (1991).

Chang, P.K., J.W. Bennett and P.J. Cotty: Association of aflatoxin biosynthesis and sclerotial development in Aspergillus parasiticus. Mycopathologia, 153, 41-48 (2002).

Chang, P.K.: Aflatoxin biosynthesis and sclerotial development in Aspergillus flavus and Aspergillus parasiticus. In: Mycotoxins in Food, Feed and Bioweapons (Eds.: M. Rai and A. Verma). Springer Science \& Business Media, p. 88 (2009).

Cotty, PJ.: Aflatoxin and sclerotial production by Aspergillus flavus: 
Influence of pH. Phytopathology, 78, 1250-53 (1988).

Cotty, P.J.: Virulence and cultural characteristics of two Aspergillus flavus strains pathogenic on cotton. Phytopathology, 79, 808-814 (1989).

Davis, N.D., S.K. Iyer and U.L. Diener: Improved method of screening for aflatoxin with a coconut agar medium. Appl. Env. Microbiol., 53 1593-1595 (1987).

Dehghan, P., F. Zaini, M. Mahmoudi, A. Jebali, P. Kordbacheh and S Rezaei: Aflatoxin and sclerotia production in clinical isolates of Aspergillus flavus group. Iranian. J. Pub. Helth., 37, 41-50 (2008).

Duran, R.M., J.W. Cary and A.M. Calvo: Production of cyclopiazonic acid, aflatrem and aflatoxin by Aspergillus flavus is regulated by veA, a gene necessary for sclerotial formation. Appl. Microbial. Biotechnol., 73, 1158 (2007).

Evancho, G.M., W.H. Sveum, L.J. Moberg and J.F. Frank: Monitoring of the food processing environment. In: Compendium Methods for the Microbiological Examination of Foods. (Eds.: F.P. Downes and K. Ito). $4^{\text {th }}$ Edn., American Public Health Association, Washington D.C., pp. 25-35 (2001).

Fakruddin, M., A. Chowdhury, M.N. Hossain and M.M. Ahmed: Characterization of aflatoxin producing Aspergillus flavus from food and feed samples. Springer Plus, 4, 159 (2015).

Fente, C.A., J.J. Ordaz, B.I. Vazquez, C.M. Franco and A. Cepeda: New additive for culture media for rapid identification of aflatoxinproducing Aspergillus strains. Appl. Env. Microbiol., 67, 4858-4862 (2001).

Galaverna, G., C. Dall'Asta, R. Corradini, A. Dossena and R. Marchelli: Cyclodextrins as selectors for mycotoxin recognition. World. Mycot. J., 1,397-406 (2008)

Ghosh, S.K., M.R. Desai, G.L. Pandya and K. Venkaiah: Airborne aflatoxin in the grain processing industries in India. American. Indust. Hyg. Asso. J., 58, 583-6 (1997).

Gorny, R.L., T. Reponen, K. Willeke, D. Schmechel, E. Robine, M. Boissier and S.A. Grinshpun: Fungal fragments as indoor air biocontaminants. Appl. Env. Microbiol., 68, 3522-3531 (2002).

Grintzalis, K., S.I. Vernardis, M.I. Klapa and C.D. Georgiou: Role of oxidative stress in sclerotial differentiation and aflatoxin B1 biosynthesis in Aspergillus flavus. Appl. Env. Microbiol, 80, 55615571 (2014).

Gupta, A. and M. Gopal: Aflatoxin production by Aspergillus flavus isolates pathogenic to coconut insect pests. World J. Microbiol. Biotechnol., 18, 329-335 (2002).

Horn, B.W., R.M. Gell, R. Singh, R.B. Sorensen and I. Carbone.: Sexual reproduction in Aspergillus flavus sclerotia: Acquisition of novel alleles from soil populations and uniparental mitochondrial inheritance. PloS One, 11, e0146169 (2016).

IARC: International Agency for Research on Cancer. Aflatoxin in some traditional herbal medicines, some mycotoxins, naphthalene and styrene. In IARC Monograph on the Evaluation of Carcinogenic Risk to Humans, Vol. 82, IARC: Lyon, France, pp. 1-599 (2002).

Khan, A.H. and S.M. Karuppayil: Fungal pollution of indoor environments and its management. Saudi. J. Biol. Sci., 19, 405-426 (2012).

Koh, H.L. and T.C. Tseng:. Isolation and identification of aflatoxin producing strains of Aspergillus flavus from stored rice. Bot. Bullet. Aca. Sinica, 16, 115-125(1975)

Lai, X., H. Zhang, R. Liu and C. Liu: Potential for aflatoxin B1 and B2 production by Aspergillus flavus strains isolated from rice samples. Saudi. J. Biol. Sci., 22, 176-180 (2015).

Lin, M.T. and J.C. Dianese: A coconut-agar medium for rapid detection of aflatoxin production by Aspergillus spp. Phytopathology, 66, 1466$1469(1976)$.

McAlpin, C.E.: An Aspergillus flavus mutant producing stipitate sclerotia and synnemata. Mycologia, 93, 552-565 (2001).

McAlpin, C.E.: Synnema and sclerotium production in Aspergillus caelatus and the influence of substrate composition on their development in selected strains. Mycologia, 96, 937-947 (2004)

Nayak, S., U. Dhua and S. Samanta: Occurrence of aflatoxigenic $A$. flavus in stored rice and rice based products of coastal Odisha, India. Int. J. Curr. Microbiol. Appl. Sci., 3, 170-181 (2014).

Nesci, A., M. Morales and M. Etcheverry: Interrelation of growth media and water activity in sclerotia characteristics of Aspergillus section Flavi. Lett. Appl. Microbiol., 44, 149-154 (2007).

Nielsen, K.F.: Mycotoxin production by indoor molds. Fung. Genet. Biol., $39,103-117(2003)$

Oyewale, M.O.: Aspergillosis and aflatoxicosis associated with tubers and leaves of sweet potatoes (Ipomoea batatas) in Osun state, South Western Nigeria. J. Env. Biol., 36, 655-660 (2015).

Pitt, J.I. and A.D. Hocking: Fungi and food spoilage. Springer Science Business Media. Springer Dordrecht Heidelberg London New York. DOI 10.1007/978-0-387-92207-2 (2009).

Rai, J.N., J.P. Tewari and A.K. Sinha: Effect of environmental conditions on sclerotia and cleistothecia production in Aspergillus. Mycopathologia, 31, 209-224 (1967).

Razzaghi-Abyaneh, M., M. Shams-Ghahfarokhi, A. Allameh, A Kazeroon-Shiri, S. Ranjbar-Bahadori, H. Mirzahoseini and R. Mohammad-Bagher: A survey on distribution of Aspergillus section Flavi in corn field soils in Iran: Population patterns based on aflatoxins, cyclopiazonic acid and sclerotia production. Mycopathologia, 161, 183-192 (2006).

Reddy, K.R.N., C.S. Reddy and K. Muralidharan: Detection of Aspergillus spp. and aflatoxin B 1 in rice in India. Food Microbiol., 26, 27-31 (2009).

Saito, M., P. Siriacha, S. Kawasugi, M. Manabe and D. Buangsuwon: Distribution and aflatoxin productivity of the atypical strains of Aspergillus flavus isolated from soils in Thailand. JSM Mycotox. 24, 41-46 (1986).

Shier, W.T., Y. Lao, T.W. Steele and H.K. Abbas: Yellow pigments used in rapid identification of aflatoxin-producing Aspergillus strains are anthraquinones associated with the aflatoxin biosynthetic pathway. Bioorg. Chem., 33, 426-438 (2005).

Singh, D., R. Thankappan, V. Kumar, N.B. Bagwan, M.S. Basu, J.R. Dobaria, G.P. Mishra and S. Chanda.: Morphological and toxigenic variability in the Aspergillus flavus isolates from peanut (Arachis hypogaea L) production system in Gujarat (India). J. Env. Biol., 36, 441-449 (2015). 